\title{
Severe obstructive sleep apnoea secondary to pressure garments used in the treatment of hypertrophic burn scars
}

\author{
M. Hubbard, I.B. Masters, G.R. Williams, A.B. Chang
}

\begin{abstract}
Severe obstructive sleep apnoea secondary to pressure garments used in the treatment of hypertrophic burn scars. M. Hubbard, I.B. Masters, G.R. Williams, A.B. Chang. (C)ERS Journals Ltd 2000.

ABSTRACT: Obstructive sleep apnoea (OSA) secondary to pressure garments used to treat hypertrophic scarring of burns has never been reported. The present study describes two children who presented with OSA following introduction of such garments for management of hypertrophic scars following severe facial and upper body burns. Complex sleep polysomnography confirmed severe OSA with desaturations sufficient to result in physiological dysfunction that significantly improved on removal of the garments.

As there is little evidence to suggest that the use of such garments alters the end result, the potentially serious side effect of obstructive sleep apnoea should be considered before their use is advised.
\end{abstract}

Eur Respir J 2000; 16: 1205-1207.
Dept of Respiratory Medicine, Mater Misericordiae Children's Hospital, South Brisbane, Queensland, Australia.

Correspondence: M. Hubbard, Dept of Paediatrics, Kingston Hospital, Galsworthy Road, Kingston Upon Thames, Surrey KT2 7QB UK. Fax: 11442089343249

Keywords: Hypertrophic scar obstructive sleep apnoea pressure garments

Received: August 121999

Accepted after revision June 142000
Healing of burns may result in hypertrophic scars and the use of special garments applying pressure over specified areas of the skin has been proposed to reduce the risk of such scarring. To date, there is yet no scientific valid proof concerning the usefulness of such garments, but several side effects have been described. This report presents data on two youngsters developing severe obstructive sleep apnoea (OSA) upon the application of such garments, an association never described before.

\section{Case 1}

A 10-yr-old male child was referred for assessment of OSA six months after falling face first into an open camp fire during an epileptic fit. He had sustained severe burns to his face, neck and chest, which had been grafted. He had severe facial skin distortion, his chin was tethered to his chest and the mouth opening was limited. Following surgery, pressure garments were fitted to prevent neck flexion and he was then noted to have nocturnal desaturations associated with noisy breathing. Examination revealed an obliterated right nostril but a normal left nostril and no tonsillar hypertrophy.

Complex sleep polysomnography (CSP) with and without garments was performed in a sleep laboratory with continuous recording of electroencephalogram (EEG), electrooculogram (EOG), nasal airflow, abdomen and chest wall movement, using respiratory inductance plesmythography, transcutaneous carbon dioxide $\left(\mathrm{Tc}, \mathrm{CO}_{2}\right)$ and oxygen saturation. With pressure garments on, shoulder shrug and paradoxical chest wall movement (defined by respiratory effort associated with abdominal and chest efforts being in the opposite direction) occurred. Gasping and restlessness were present in rapid eye movement
(REM) sleep and desaturations to the low $80 \%$ 's were seen with obstructive respirations. $\mathrm{Tc}, \mathrm{CO}_{2}$ rose from $44 \mathrm{mmHg}$ to $54 \mathrm{mmHg}$. After removal of the garments, recession and paradoxical breathing immediately decreased and although several obstructive hypopnoeas (as defined by an amplitude amplitude reduction in flow $\geq 50 \%$, that lasted longer than the preceding two breaths [1]) occurred, these were not associated with desaturation. EEG did not show any epileptiform waves.

\section{Case 2}

A 14-yr-old child under treatment with the psychiatrists for nocturnal enuresis was referred 6 months after sustaining deep partial thickness burns to $40 \%$ of his body including face, neck and chest. These occurred whilst lighting a bonfire with methylated spirits. Following introduction of an upper body pressure garment with hood, his previously mild snoring worsened and his occasional nocturia increased to such a frequency as to require inpatient attention. He started snorting, had marked restlessness at night, daytime somnolence and complained of morning headache. His forced expiratory volume in one second (FEV1) and forced vital capacity (FVC) in the garment were both reduced by $25 \%$. He had a family history of nonproblematic snoring. He fell asleep three times during the examination, snored loudly and was awoken by obstructive events.

CSP was performed showing significant OSA. There were repeated desaturations below $80 \%$ to a minimum of $66 \%, \mathrm{CO}_{2}$ retention $\left(\mathrm{Tc}, \mathrm{CO}_{2}\right.$ increased from $46 \mathrm{mmHg}$ at the start to $59 \mathrm{mmHg}$ ) and arousals associated with obstructive events. Although he continued to snore after removal of his garments there were no further desaturations 
(fig. 1). His $\mathrm{Tc}, \mathrm{CO}_{2}$ returned to initial levels within $1 \mathrm{~h}$ of removing the pressure garment.

\section{Discussion}

The present case studies have described how the use of pressure garments can lead to severe OSA, a previously unreported association. Case one was already at risk of obstructive events due to his skin distortion, trismus, loss of a nasal airway and flexural neck contractions and case two had a preexisting risk of OSA with his positive family history. OSA causes significant morbidity in children [24]. There are a variety of manifestations associated with OSA including daytime somnolence, fatigue, deterioration in memory and learning, difficult behaviour and in severe cases, neurodevelopmental delay. Energy expenditure from the increased work of breathing can lead to failure to thrive. Symptoms on waking may include headache, dry mouth and disorientation [2-4]. Although arterial pressures should return to normal after ventilation resumes, apnoeas which are prolonged or in quick succession can cause persistently raised arterial pressure and right heart strain. This, in addition to hypoxia, increases the risk of arrhythmia's and sudden death, especially in infants [5].

The degree of hypoxia seen in the two patients may have led to irreversible changes if the garments had been worn for the 1-3 yr period requested by the surgeon. The use of a tight fitting face garment may lead to OSA by changing tissue elastance or resistance. An upper chest pressure garment could theoretically create a restrictive chest wall (as seen in the FVC of case two) and a reduction in functional residual capacity similar to reductions seen in scoliosis $[6,7]$. This may limit ability to increase tidal volume after periods of hypopnoea and apnoea [6], Restriction of chest wall expansion by a constrictive garment may also limit minute ventilation or increase the ventilation perfusion ratio mismatch [6]. Pressure garment treatment is usually prolonged, expensive and compliance is low. There is no consensus for optimal pressure [7], and despite precise measurements at fitting the pressure [8] applied is inconsistent. Moreover, facial pressure garments can alter facial growth and tooth position in children [9] and other complications have been described $[10,11]$.

These case reports emphasize that the use of pressure garments in the management of hypertrophic burn scars a)

C3-A2

LE-A2

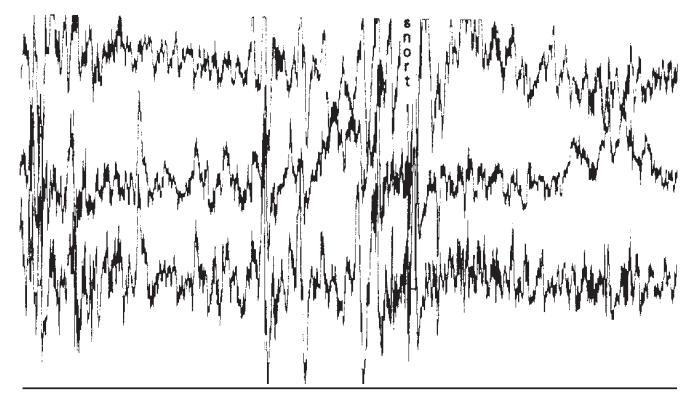

RIB-RF M mannd b)

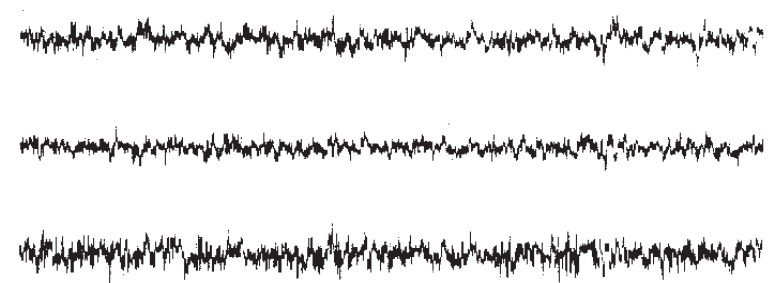

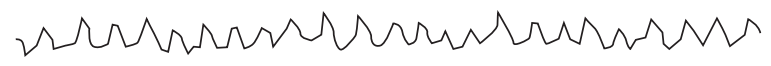

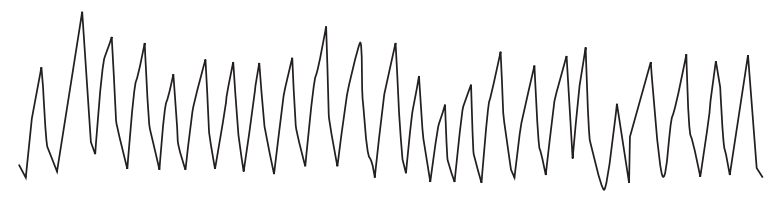

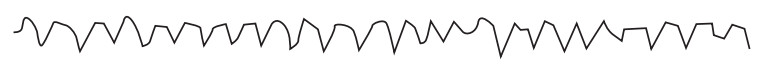

$50 \mathrm{~Hz}$ Notch, LF=0.5, HF=70, $100 \mu \mathrm{V}, 102 \mathrm{~S}$

Fig. 1. - Traces from the complex polysomnography of case two. Tracing with a) garment on shows paradoxical respirations, disrupted flow and desaturations associated with obstructive events which resolve on b) removal of the garment. C3-A2: electroencephalogram-left central lead O2; O2-A1: electroencephalogram-right occipital lead; RI-A1: right electrooculogram; RIB-RF: chest plethysmography; ABDO-RF: respitrace; FLOW-RF: nasal flow; $\mathrm{S}_{\mathrm{a}} \mathrm{O}_{2}-\mathrm{RF}$ : transcutaneous oxygen saturation (measured using pulse oximetry); LE-A2: electrooculogram has been removed from the screen because of electrical interference to the signal; RF: reference. 
may cause or amplify existing obstructive sleep apnoea and lead to significant morbidity. As there is little scientific evidence to support the widespread use of such garments, physicians need to be aware of the potential for such significant complications, especially if pre-existing risks are present.

\section{References}

1. Masters IB, Harvey JM, Wales PD, O'Callaghan MJ, Harris MA. Clinical versus polysomnographic profiles in children with obstructive sleep apnoea. J Paediatr Child Health 1999; 35: 49-54.

2. Frank Y, Kravath RE, Pollack CP, Weitzman ED Obstructive sleep apnea and it's therapy: clinical and polysomnographic manifestations. Pediatr 1983; 71: 737-742.

3. Brouillette RT, Fernbach SK, Hunt CE. Obstructive sleep apnea in infants and children. J Pediatr 1982; 100: 31-40.

4. Brouililette R, Hanson D, David R, et al. A diagnostic approach to suspected obstuctive sleep apnea in children. J Pediatr 1984; 105: 10-14.
5. Guilleminault C, Powell N, Heldt G, et al. Small upper airway in near miss sudden infant death infants and their families. Lancet 1986; 1: 402-407.

6. Smyth R, Chapman K, Wright TA, Crawford JS, Rebuck AS. Ventilatory patterns during hypoxia, hypercapnia and exercise in adolescents with mild scoliosis. Pediatr 1986; 77: 692-697.

7. Kearon C, Viviani GR, Killian KJ. Factors determining pulmonary function in adolescents with idiopathic thoracic scoliosis. Am Rev Respir Dis 1993; 148: 288-294.

8. Editorial. Respiratory function in scoliosis. Lancet 1985; 1: $845-846$.

9. Giele H, Liddiard K, Booth K, Wood F. Anatomical variations in pressures generated by pressure garments. Plast Reconstr Surg 1998; 101: 399-406.

10. Fricke N, Omnell M, Dutcher K, Hollender L, Odont D, Engrav L. Skeletal and dental disturbances after facial burns and pressure garments. J Burn Care Rehabil 1996; 17: $338-345$.

11. Leung K, Cheng JYC, Ma GFY, Clark JA, Leung PC. Complications of pressure therapy for post-burn hypertrophic scars. Biomechanical analysis based on 5 patients. Burns Include Therm Inj 1984; 10: 434-438. 